\title{
Hop-on hop-off: importin- $\alpha$-guided tours to the nucleus in innate immune signaling
}

\author{
Lennart Wirthmueller $^{1}$ *, Charlotte Roth ${ }^{2}$, Mark J. Banfield ${ }^{1}$ and Marcel Wiermer ${ }^{2}$ * \\ ' Department of Biological Chemistry, John Innes Centre, Norwich Research Park, Norwich, UK \\ ${ }^{2}$ Albrecht-von-Haller-Institute for Plant Sciences, Department of Plant Cell Biology, Georg-August-University Göttingen, Göttingen, Germany
}

\author{
Edited by: \\ Laurent Deslandes, Centre National \\ de la Recherche Scientifique, France \\ Reviewed by: \\ Mahmut Tör, University of Worcester, \\ UK \\ Wladimir Igor Tameling, Wageningen \\ University, Netherlands \\ ${ }^{*}$ Correspondence: \\ Lennart Wirthmueller, Department of \\ Biological Chemistry, John Innes \\ Centre, Norwich Research Park, \\ Norwich, NR4 7UH, UK. \\ e-mail: lennart.wirthmueller@jic.ac.uk; \\ Marcel Wiermer, Albrecht-von- \\ Haller-Institute for Plant Sciences, \\ Department of Plant Cell Biology, \\ Georg-August-University Göttingen, \\ Julia-Lermontowa-Weg 3, 37077 \\ Göttingen, Germany. \\ e-mail:wiermer@uni-goettingen.de
}

Nuclear translocation of immune regulatory proteins and signal transducers is an essential process in animal and plant defense signaling against pathogenic microbes. Import of proteins containing a nuclear localization signal (NLS) into the nucleus is mediated by nuclear transport receptors termed importins, typically dimers of a cargo-binding $\alpha$-subunit and a $\beta$-subunit that mediates translocation through the nuclear pore complex. Here, we review recent reports of importin- $\alpha$ cargo specificity and mutant phenotypes in plantand animal-microbe interactions. Using homology modeling of the NLS-binding cleft of nine predicted Arabidopsis $\alpha$-importins and analyses of their gene expression patterns, we discuss functional redundancy and specialization within this transport receptor family. In addition, we consider how pathogen effector proteins that promote infection by manipulating host cell nuclear processes might compete with endogenous cargo proteins for nuclear uptake.

Keywords: importin- $\alpha$, nuclear protein import, nucleocytoplasmic transport, Arabidopsis, innate immunity

\section{HOP-ON HOP-OFF: IMPORTIN-MEDIATED NUCLEAR PROTEIN IMPORT}

In eukaryotic cells, nuclear transport receptors (NTRs) of the importin- $\alpha$ family recognize and bind to canonical nuclear localization signal (NLS)-containing cargo proteins in the cytoplasm and link them to importin- $\beta$, the NTR that facilitates passage of the ternary complex through the nuclear pore complex (NPC) into the nucleus. Cargos may contain one (monopartite) or two (bipartite) NLS sequence motifs and directional binding to and release from the importin- $\alpha / \beta$ heterodimer is imposed by the nucleotide-binding state of Ran, a small guanosine-5'triphosphatase (GTPase) that cycles between GTP-bound nuclear and guanosine-5'-diphosphate (GDP)-bound cytoplasmic states (Terry etal., 2007; Meier and Somers, 2011). The RanGDPRanGTP gradient across the nuclear envelope (NE) is generated by the asymmetric distribution of two regulators, RanGAP in the cytoplasm and RanGEF in the nucleus that is associated with chromatin and drives nuclear cargo release upon binding of RanGTP to importin- $\beta$. After dissociation of the import complex and cargo delivery into the nucleus, importin- $\beta$ bound to RanGTP is recycled to the cytoplasm, whereas importin- $\alpha$ interacts with the RanGTPbound export receptor CAS for recycling of cargo-free importin- $\alpha$ back to the cytoplasm. In the cytoplasm, RanGAP stimulates GTP hydrolysis on Ran to release the importins for another round of import (Stewart, 2007).

$\alpha$-importins typically consist of an $\mathrm{N}$-terminal auto-inhibitory importin- $\beta$-binding (IBB) domain followed by a series of ten armadillo (ARM) repeats that form the NLS-binding cleft
(Goldfarb et al., 2004; Figures 1A,B). The flexible IBB domain not only connects importin- $\alpha$ to importin- $\beta$ but also contains a cluster of basic amino acids that competes with NLS-cargos for binding to the ARM-repeat domain of importin- $\alpha$. Thus, the IBB domain is involved in regulating both formation of the trimeric import complex in the cytoplasm and release of cargo in the nucleus after the IBB domain is freed from importin- $\beta$ by RanGTP (Görlich et al., 1996a; Kobe, 1999; Stewart, 2007). Following cargo release in the nucleus $\alpha$-importin is exported to the cytoplasm by a complex of the export carrier CAS and RanGTP (Goldfarb et al., 2004; Matsuura and Stewart, 2004).

Stimulus-induced nuclear translocation and/or accumulation of signaling molecules and transcriptional regulators are essential for the coordinated relay of defense signals in both plant and animal innate immune responses to microbial pathogens. Inside the nucleus, these signals direct the expression of defenserelated genes. In addition, it has become increasingly evident that not only do host resistance components show dynamic partitioning between the cytoplasm and the nucleus, but also that a significant number of animal and plant pathogen virulence factors exploit host cell nuclear import pathways to act directly within the nucleus and promote disease. In this review, we provide an overview of recent studies reporting importin- $\alpha$ cargo selectivity in animal and plant innate immunity and discuss potential promiscuity within the Arabidopsis import receptor family. We also consider how microbial virulence factors may hijack the nuclear import machinery to manipulate host cell nuclear processes. 


\section{IMPORTIN- $\alpha$ PARALOGS IN Arabidopsis thaliana}

Although the Saccharomyces cerevisiae genome encodes only a single importin- $\alpha$ (Yano et al., 1992), several paralogs have been reported in most higher eukaryotes - seven in humans, six in mouse, three in Drosophila, five in rice, and nine in Arabidopsis (Ouyang etal., 2007; Ratan etal., 2008; Hu etal., 2010; Kelley et al., 2010; Merkle, 2011). Conceivably, expansion of the importin- $\alpha$ gene family in multicellular eukaryotes reflects adaptation toward a more complex regulation of nuclear import. Several mammalian importin- $\alpha$ paralogs show tissue-specific expression patterns (Köhler etal., 1997; Tsuji et al., 1997; Yasuhara etal., 2007), and nuclear import of some cargo proteins is preferentially mediated by specific importin- $\alpha$ adapters (Miyamoto et al., 1997; Nadler et al., 1997; Köhler et al., 1999; Melén et al., 2003; Quensel et al., 2004). In Arabidopsis importin- $\alpha 1-4, \alpha 6$, and $\alpha 9$ are ubiquitously expressed (Figure 1C). However, there is controversy from different profiling techniques regarding the levels and tissuespecificity of importin- $\alpha 5, \alpha 7$, and $\alpha 8$ expression (Meyers et al., 2004; Bhattacharjee et al., 2008; Hruz et al., 2008; Huang et al., 2010). For example, although Huang et al. (2010) report specific expression of importin- $\alpha 8$ in rosette/cauline leaves and flowers, a search for genes regulated by the male germ line-specific transcription factor (TF) DUO1 suggests that importin- $\alpha 8$ is a DUO1 target gene that is specifically expressed in the male germ line (Borg et al., 2011). These data indicate that importin- $\alpha 8$ may have a distinct function during pollen development. Notably, importin- $\alpha 8$ does not have an IBB domain (Figure 1B) suggesting that it lacks both the capacity to bind importin- $\beta$ and the auto-inhibitory mechanisms that are conserved in the other $\alpha$-importins. Therefore, it remains to be tested if importin- $\alpha 8$ can function as a NTR and whether the loss of the IBB domain is a consequence of specialization in pollen development.

The comparably high number of $\alpha$-importins in Arabidopsis can only partially be rationalized by tissue-specific expression of single paralogs. Alternatively, multiple paralogs might have evolved to transport specific cargos. Indeed, the NLS from the rice COP 1 protein binds in vitro the two rice importins $\alpha$ la and $\alpha 1 b$, but not importin- $\alpha 2$ (Jiang et al., 2001). This, and other examples outlined below, provides evidence for cargo specificity of $\alpha$-importins and it appears likely that higher eukaryotes are equipped with an array of $\alpha$-importins that accumulate to different levels and exhibit different affinities for distinct cargos. Transcriptional and post-translational regulation of importin- $\alpha$ protein levels in response to environmental stimuli would constitute a flexible system to alter nuclear import kinetics and specificities in changing environments.

\section{SEOUENCE DIVERSITY IN Arabidopsis $\alpha$-IMPORTINS}

Resolved crystal structures of $\alpha$-importins from yeast, human, mouse, and rice revealed strong structural conservation of the ARM repeat domains that form the NLS binding sites (Conti et al., 1998; Kobe, 1999; Fontes et al., 2003; Chang et al., 2012). ARM repeats from yeast, human, and mouse $\alpha$-importins can be superimposed with a root mean square deviation of less than $1.8 \AA$ and amino acids that contribute to the NLS binding sites occupy very similar positions in these structures. We used homology modeling to characterize conservation of the NLS binding site among the nine Arabidopsis $\alpha$-importins. As in $\alpha$-importins from other species, a conserved array of Trp/Asn pairs protruding from the third helix of the ARM repeats $(\mathrm{H} 3)$ forms the core of the major and minor NLS binding sites in Arabidopsis $\alpha$-importins (Figure 1A). Previous comparative analysis revealed that major determinants of specificity are (i) the amino acid positioned three residues upstream of the conserved Trp, and (ii) residues that constitute the loops connecting the $\mathrm{H} 3$ and $\mathrm{H} 1$ helices (Marfori et al., 2012). Notably, the Trp/Asn array at the minor NLS binding site is not entirely conserved in plant $\alpha$-importins (Figure 1D and Table 1). As some plant NLSs specifically bind to the minor NLS binding site (Chang et al., 2012) it will be interesting to test whether these divergent amino acids determine binding to specific NLSs.

\section{IMPORTIN- $\alpha$ CARGO SPECIFICITY IN ANIMAL IMMUNE RESPONSES}

Both animal and plant innate immune systems have evolved pattern recognition receptors (PRRs) to detect microbe-associated molecular patterns (MAMPs) and defend against pathogens (Nürnberger et al., 2004; Ausubel, 2005). In addition to MAMP detection, the plant innate immune system also imparts pathogenspecific recognition via nucleotide-binding/leucine-rich repeat immune sensors (NLRs) that detect the actions of isolatespecific pathogen virulence factors, termed effectors (Jones and Dangl, 2006). In contrast, animal NLRs detect MAMPs inside host cells (Kanneganti et al., 2007a; Ronald and Beutler, 2010; Maekawa et al., 2011). Activation of both NLRs and PRRs initiates signaling cascades that convey the biotic stress stimulus into the host cell nucleus to alter defense gene expression. Thus, stimulus-induced changes in the NPC permeability of signal transducers, immune and transcriptional regulators represent an important mechanism for controlling defense-associated gene expression.

Changes in nuclear translocation rates are often achieved via post-translational protein modifications leading to conformational changes that expose or conceal NLSs or nuclear export sequences (NESs). For example, gene expression changes in mammalian innate immunity are largely governed by the induced nuclear translocation of the NF- $\kappa$ B family of Rel-type TFs. Nuclear accumulation of NF- $\kappa \mathrm{B}$ is controlled by its association with I $\mathrm{B}$ proteins. Depending on the type of $\mathrm{I} \kappa \mathrm{B}$, these proteins either sequester NF- $\kappa$ B in the cytoplasm by masking its NLS, or prevent its ability to bind to chromatin due to a strong NES in ІкB that directs dominant nuclear export over nuclear import (Johnson etal., 1999; Huang etal., 2000; Malek etal., 2001). Signal-dependent phosphorylation by IкB-kinase targets IкB for proteolysis, thereby allowing NF- $\mathrm{B}$ nuclear import to activate defense gene expression. In human cells, the closely related importins $\alpha 3$ and $\alpha 4$ are the two main isoforms responsible for nuclear import of NF- $\kappa$ B p50/p65 heterodimers following I degradation. Whereas the major NLS binding site of importin$\alpha 3$ binds to $\mathrm{p} 50$, the minor NLS binding site mediates association with p65 (Fagerlund et al., 2005).

Innate immune responses in Drosophila are also controlled at the level of nuclear transport. Upon activation of the Toll signaling cascade, NF-кB/Rel-type TFs translocate to the nucleus 


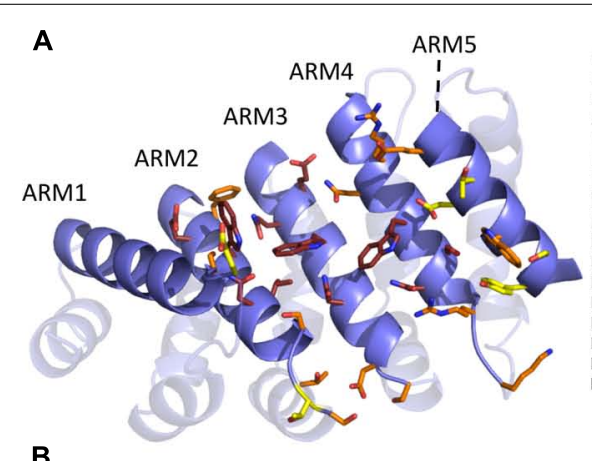

B

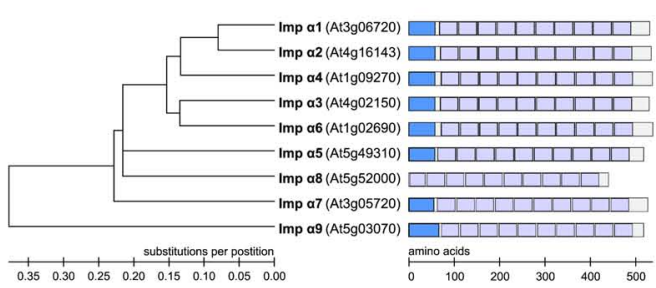

D

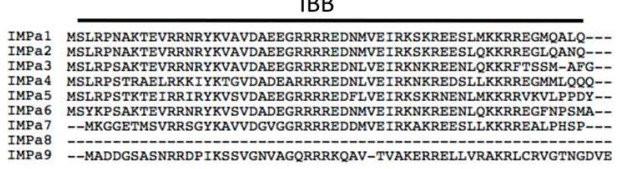

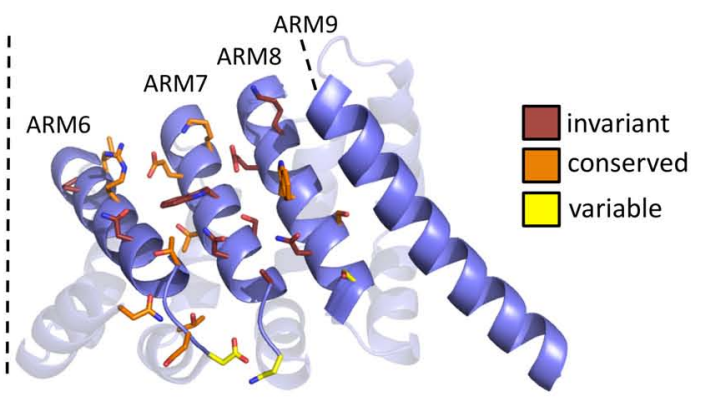

C

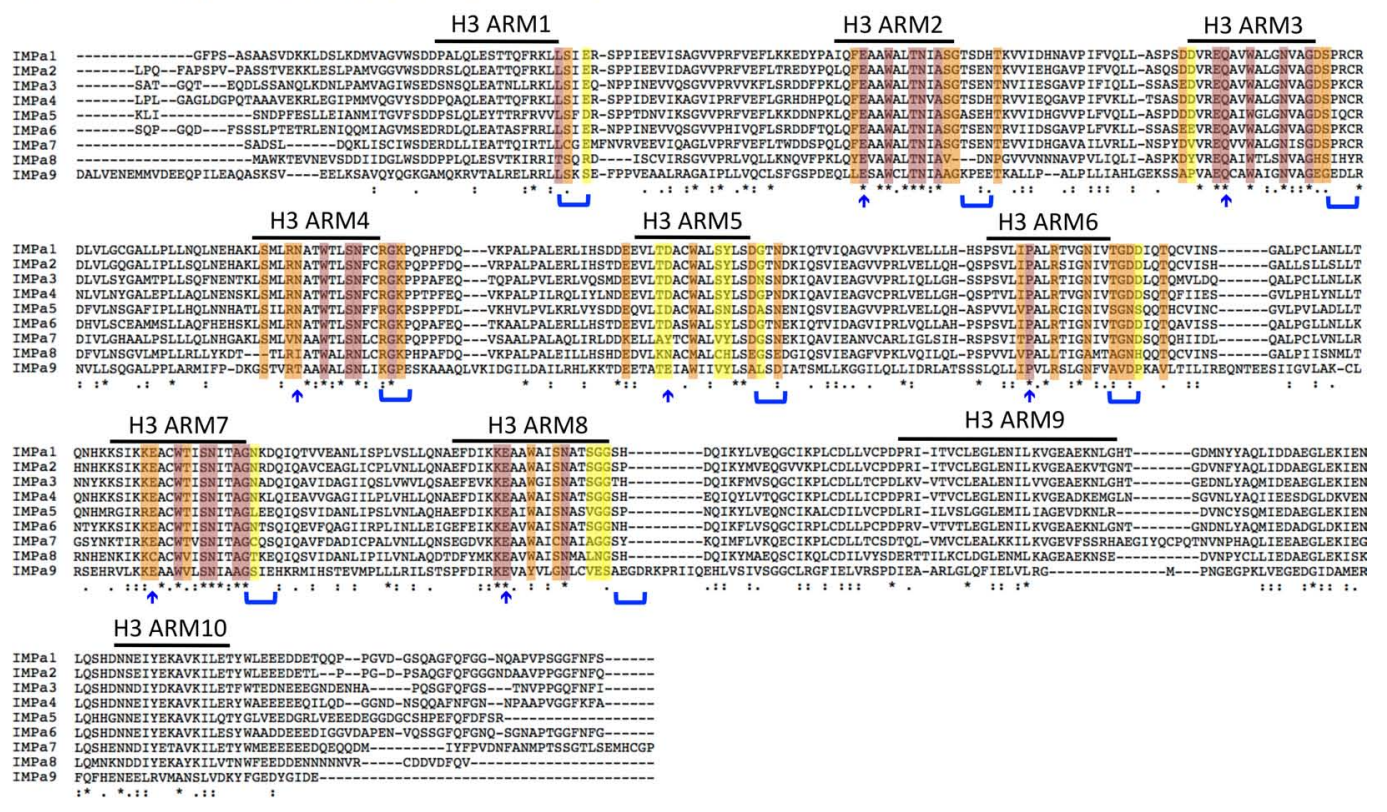

FIGURE 1 | Expression profile and sequence comparison of Arabidopsis importins $\alpha \mathbf{1 - 9}$. (A) Homology model of the ARM repeat domain of Arabidopsis importins $\alpha 1-9$ based on the structure of rice importin- $\alpha 1$ a (RCSB identifier 4B8J, Chang et al., 2012). Left image: major NLS binding site. Right image: minor NLS binding site. Amino acids that are likely to contribute to the NLS binding sites are shown in stick representation. The color code indicates the level of conservation in Arabidopsis a-importins. (B) Phylogenetic tree constructed using neighbor joining in Molecular Evolutionary Genetics Analysis (MEGA) v4.0 (Tamura et al., 2007). Importin- $\alpha 9$ was used to root the tree. Scale bar represents amino acid substitutions per position. Schematic representation: The different protein domains are depicted as boxes within the full length protein sequence. Importin- $\beta$-binding domains are shown in dark blue and the ten Armadillo repeat domains are shown in light blue. Scale bar shows number of amino acids. (C) Gene expression data were gathered from the Genevestigator database (https://www.genevestigator.com/gv/; Hruz etal., 2008). Data referring to whole tissues were chosen for comparison of expression levels. Numbers represent linear signal intensity values of the given gene in the indicated tissues. Heat map indicates low signal intensity (green) to high signal intensity (red). (D) Multiple sequence alignment of full-length protein sequences performed using ClustalW2 (http://www.ebi.ac.uk/Tools/msa/clustalw2/; Larkin etal., 2007). Color code for conservation as in A. Blue arrows and parenthesis indicate candidate amino acids that are predicted to contribute to the NLS binding sites based on analysis of yeast, mouse, and human $\alpha$-importins (Marfori et al., 2012). Variations in these motifs are likely to determine specificity of $\alpha$-importins for NLS binding. 
Table 1 | Some plant $\alpha$-importins diverge from the otherwise conserved pattern of amino acids protruding from ARM H3 helices that form the core of the NLS binding sites. The amino acid pairs denoted as consensus sequence (column two) are conserved in $\alpha$-importins from yeast, human, mouse, and Drosophila, as well as the remaining $\alpha$-importins from Arabidopsis and rice. Amino acids in blue bold font indicate divergence from the consensus sequence whereas "cons." indicates conservation of the consensus sequence.

\begin{tabular}{|c|c|c|c|c|c|c|}
\hline ARM repeat & $\begin{array}{l}\text { Consensus } \\
\text { sequence }\end{array}$ & $\begin{array}{l}\text { At } \\
\text { importin } \alpha 5\end{array}$ & $\begin{array}{l}\text { At } \\
\text { importin } \alpha 8\end{array}$ & $\begin{array}{l}\text { At } \\
\text { importin } \alpha 9\end{array}$ & $\begin{array}{l}\text { Os importin } \\
\text { Os07g48880 }\end{array}$ & $\begin{array}{l}\text { Os } \\
\text { importin } \alpha 2\end{array}$ \\
\hline ARM2 & Trp/Asn & cons. & cons. & cons. & cons. & cons. \\
\hline ARM3 & Trp/Asn & cons. & cons. & cons. & cons. & cons. \\
\hline ARM4 & Trp/Asn & cons. & cons. & cons. & cons. & cons. \\
\hline ARM5 & Trp/Tyr & Trp/Asn & Met/His & cons. & cons. & cons. \\
\hline ARM6 & Arg/Asn & cons. & Leu/Ala & cons. & Thr/Arg & cons. \\
\hline ARM7 & Trp/Asn & cons. & cons. & cons. & Leu/Asn & cons. \\
\hline ARM8 & Trp/Asn & cons. & cons & Tyr/Asn & cons. & Tyr/Asn \\
\hline
\end{tabular}

in a process that is dependent on nuclear transport factor2 (NTF-2), an essential component of nuclear trafficking that acts as nuclear import receptor for RanGDP to replenish the nuclear Ran pool (Ribbeck et al., 1998; Smith et al., 1998; Bhattacharya and Steward, 2002). Whether NTF-2 directly binds Rel proteins or indirectly affects their nuclear import rates by regulating the function of Drosophila $\alpha$-importins remains to be determined.

Like NF-кB, signal transducers and activators of transcription (STAT) proteins are a family of latent cytoplasmic TFs, consisting of seven members in mammals. Upon cytokine activation of the canonical STAT-signaling pathway, tyrosine phosphorylation induces STAT homo- or hetero-dimerization and subsequent importin- $\alpha$-dependent nuclear import (Lim and Cao, 2006). Activated STAT1 homodimers and STAT1/STAT2 heterodimers interact with importin- $\alpha 5$ (Melén etal., 2001; Fagerlund et al., 2002) whereas RNAi-mediated silencing of importin- $\alpha 3$ but not of other tested importin- $\alpha$ family members impairs nuclear translocation of STAT3, but not of STAT1 (Liu et al., 2005). This indicates that different $\alpha$-importins can have distinct STAT protein binding preferences.

Further examples of vertebrate immune regulatory proteins that contain NLSs and can shuttle into the nucleus are the NLRs CIITA and NLRC5. Both these proteins function through association with DNA-binding proteins to regulate MHC class II and class I gene expression, respectively (Spilianakis et al., 2000; Cressman et al., 2001; Meissner et al., 2012). Correlating potential importin- $\alpha$ binding specificities for CIITA and NLRC5 remains to be determined.

\section{IMPORTIN- $\alpha$ CARGO SPECIFICITY IN PLANT INNATE IMMUNITY}

In rice, the intracellular kinase domain of the PRR XA21 carries a functional NLS and translocates to the nucleus after cleavage from the activated receptor, probably to modulate transcription (Park and Ronald, 2012). Also, several NLRs exhibit nucleocytoplasmic partitioning, including Arabidopsis RPS4, snc1 and RRS1-R, tobacco N, barley MLAs, and potato Rx (Deslandes et al., 2003; Burch-Smith etal., 2007; Shen et al., 2007;
Wirthmueller et al., 2007; Cheng et al., 2009; Slootweg et al., 2010; Tameling et al., 2010). Except for MLA and Rx, these proteins possess predicted NLSs and it appears that mono- or bipartite NLSs are widespread among Arabidopsis NLRs (Shen and SchulzeLefert, 2007; Caplan et al., 2008; Liu and Coaker, 2008). However, experimental proof for the function of these motifs has only been provided for RPS4 (Wirthmueller et al., 2007) and it is not understood how nucleocytoplasmic partitioning of these immune sensors is regulated.

Besides NLRs, the dynamic translocation of several plant immune regulatory proteins is a key factor in defense pathway regulation. In healthy Arabidopsis cells, the transcriptional co-activator NPR1 is retained partially in the cytoplasm as a homooligomeric complex. Changes in the cell's redox potential, induced by the defense hormone salicylic acid, promotes release of NPR1 monomers and their nuclear accumulation, presumably via exposure of an obscured NLS (Kinkema et al., 2000; Mou et al., 2003; Tada et al., 2008). A negative regulator of cell death, the Arabidopsis zinc finger protein LSD1, antagonizes transcriptional activity of the nucleocytoplasmic shuttling leucine-zipper TF, bZIP10, by sequestering bZIP10 in the cytoplasm. Dissociation in response to pathogens is thought to unmask the NLS of bZIP10, permitting its nuclear translocation and expression of target genes (Kaminaka et al., 2006). Another report suggests that LSD1 itself localizes to nuclei, as Pisum sativum LSD1 is nuclear when transiently expressed in Arabidopsis protoplasts. PsLSD1 nuclear localization is mediated by its zinc finger motifs that interact with several Arabidopsis $\alpha$-importins and may constitute a novel NLS (He et al., 2011). The cell death pathway repressed by LSD1 depends on the activities of EDS1 and PAD4, two key regulators of basal resistance and immunity triggered by Toll interleukin-1 receptor (TIR)-type NLRs (Aarts et al., 1998; Feys et al., 2001; Wiermer et al., 2005). EDS1 harbors a predicted NLS and NES and forms dynamic nucleocytoplasmic complexes with PAD4 and SAG101, yet NTR binding-specificities responsible for nuclear targeting remain elusive (Feys et al., 2005; Garcia et al., 2010).

Evidence of importin- $\alpha$ cargo specificity in plants comes from a report by Kanneganti et al. (2007b). Silencing of Nicotiana benthamiana importin- $\alpha 1$ and $\alpha 2$ inhibits nuclear targeting of the 
transiently expressed Phytophthora infestans effectors Nuk6 and Nuk7 while nuclear import of Nuk12 is unaffected.

Constitutive immune signaling induced by a point mutation in SNC1, an Arabidopsis TIR-type NLR, is partially suppressed by mutations in importin- $\alpha 3$ (Palma et al., 2005). A pool of active sncl protein is found in nuclei and auto-immunity is abolished by a snc1-NES fusion (Cheng et al., 2009). Overexpression of GFP-tagged SNC1-4 (a mutant version of snc1-1) in wild type Arabidopsis protoplasts results in an entirely nuclear accumulation of the fusion protein, while the same construct is nucleocytoplasmic in protoplasts lacking importin- $\alpha 3$ (Zhu et al., 2010). Although this makes importin- $\alpha 3$ a candidate NTR of SNC1-4 it remains to be tested whether SNC1-4 binds importin- $\alpha 3$ directly. Alternatively, importin- $\alpha 3$ may be required for nuclear import of signaling components activated by sncl. Partial suppression of the snc1-1 phenotype by knock-out of importin- $\alpha 3$ indicates that other $\alpha$-importins might work redundantly with importin- $\alpha 3$ in sncl-triggered immunity.

A knock-out of Arabidopsis importin- $\alpha 4$ results in a rat (resistant to Agrobacterium transformation) phenotype (Bhattacharjee et al., 2008). Transformation by Agrobacterium requires active nuclear import of the transfer DNA/protein complex (T-complex). Two Agrobacterium effectors, VirD2 and VirE2 are essential for plant transformation and both proteins carry NLSs, providing a molecular link between the T-complex and the host's nuclear import machinery (Gelvin, 2010; Pitzschke and Hirt, 2010). Although VirE2 and VirD2 can interact with several Arabidopsis $\alpha$-importins, only a knock-out of importin- $\alpha 4$ impairs host transformation (Bhattacharjee et al., 2008). Significantly, the rat phenotype is not only complemented by importin- $\alpha 4$ overexpression but also by overexpression of six other Arabidopsis $\alpha$-importins. This suggests that although importin- $\alpha 4$ is the most relevant NTR for the T-complex other $\alpha$-importins can complement loss of importin- $\alpha 4$ function when their protein levels are increased. These results are in agreement with findings in yeast which show that nuclear import of different NLSs, with varying affinities for importin- $\alpha$, is largely governed by the rate of NLS/importin- $\alpha$ complex formation (Riddick and Macara, 2005; Hodel et al., 2006; Timney et al., 2006). Thus, nuclear import rates can be elevated by either increasing protein levels of the cargo or importin- $\alpha$, or by increasing the affinity of the NLS for the NTR.

\section{HOLD ON TIGHT - NUCLEAR PATHOGEN EFFECTORS AND THE IMPORTIN- $\alpha /$ NLS AFFINITY CONTROVERSY}

Notably, the "optimal" binding affinity of a NLS for importin- $\alpha$ is still controversial. Several in vitro studies reported dissociation constants in the low nanomolar range based on indirect affinity measurements (Hodel et al., 2001; Timney et al., 2006; Kosugi et al., 2008). Two other studies determined NLS/importin- $\alpha$ affinities in vitro by isothermal titration calorimetry and found $\mathrm{K}_{\mathrm{d}}$ values of $\sim 3$ and $\sim 48 \mu \mathrm{M}$, respectively (Ge et al., 2011; Lott et al., 2011). $K_{d}$ values in the low nanomolar range are difficult to reconcile with the finding that in vivo importin- $\alpha$-mediated nuclear import cannot be saturated even by $\sim 20$-fold molar excess of NLScargo suggesting that the actual dissociation constants in the cytoplasm are significantly higher, possibly due to competitive binding of other cytoplasmic proteins to importin- $\alpha$ (Timney et al., 2006).
Indeed, a non-invasive FRET/FLIM approach revealed $\mathrm{K}_{\mathrm{d}}$ values in the low micromolar range in mammalian cells and substantiates the idea that formation of the NLS/importin- $\alpha$ complex in the cytoplasm is the rate-limiting event for nuclear import (Cardarelli et al., 2009). Artificial NLS peptides with extremely low $\mathrm{K}_{\mathrm{d}}$ values interfere with dissociation of the NLS/importin- $\alpha$ complex in the nucleus and prevent recycling of importin- $\alpha$ to the cytoplasm (Kosugi et al., 2008). Consequently, these peptides inhibit nuclear import. Whether some cargo proteins with high-affinity NLS such as the cap-binding complex remain bound to importin- $\alpha$ in the nucleus is still matter of discussion (Görlich et al., 1996b; Dias et al., 2009, 2010).

A significant number of host-targeted pathogen effector proteins localize entirely to host cell nuclei, indicating active nuclear import or passive diffusion through the NPC and sequestration in the nucleus (Deslandes and Rivas, 2011; Caillaud et al., 2012a,b). Generally, nuclear localization correlates with NLS motifs in the primary sequence suggesting that these effectors exploit the host cell's nuclear import machinery for nuclear translocation. To what extent nuclear-targeted effectors need to compete with endogenous cargos is not understood. Effectors presumably act at relatively low protein levels to prevent activation of host defense. Given their low abundance and requirement for efficient nuclear targeting, effector NLSs might be an interesting source of high-affinity NLSs. Positioning effector NLSs within the above functional affinity limits will reveal whether pathogens evolved atypical NLS motifs that promote efficient nuclear import of effectors. Given the importance of nucleocytoplasmic transport for some immune pathways it has been hypothesized that microbial effectors might not only exploit but also manipulate or mimic components of the nuclear translocation machinery to subvert defense signaling. It is known that some animal viruses interfere with nucleocytoplasmic trafficking (Cohen et al., 2012), however, for microbial pathogens experimental proof for this hypothesis is lacking.

The reports discussed in this review substantiate the idea that tissue-specific expression, importin- $\alpha$ protein levels and sequence variation in the NLS binding cleft determine which importin- $\alpha$ functions as NTR for a cargo protein. However, more thorough analyses of plant NLS/importin- $\alpha$ complexes both in vitro and in vivo using emerging quantitative cell biology approaches are required to understand the complex regulation of nuclear import. Finally, many nuclear proteins do not have canonical NLS motifs. Although other import routes such as direct binding to importin$\beta$ (Marfori et al., 2011) or binding to other NTRs (Genoud et al., 2008) can account for some of these observations, the quest for novel NLSs continues.

\section{ACKNOWLEDGMENTS}

We apologize to all colleagues whose work could not be cited due to space limitations. We thank Jacqueline Monaghan for critical reading of the manuscript. Mark J. Banfield acknowledges the BBSRC (grant BB/J004553/1), the John Innes Foundation and the Gatsby Charitable Foundation for funding. Lennart Wirthmueller is supported by a FEBS long-term fellowship. Charlotte Roth and Marcel Wiermer acknowledge the Deutsche Forschungsgemeinschaft (DFG) for funding. 


\section{REFERENCES}

Aarts, N., Metz, M., Holub, E., Staskawicz, B. J., Daniels, M. J., and Parker, J. E. (1998). Different requirements for EDS1 and NDR1 by disease resistance genes define at least two $\mathrm{R}$ gene-mediated signaling pathways in Arabidopsis. Proc. Natl. Acad. Sci. U.S.A. 95, 10306-10311.

Ausubel, F. M. (2005). Are innate immune signaling pathways in plants and animals conserved? Nat. Immunol. 6, 973-979.

Bhattacharjee, S., Lee, L., and Oltmanns, H. (2008). IMPa-4, an Arabidopsis importin- $\alpha$ isoform, is preferentially involved in Agrobacterium-mediated plant transformation. Plant Cell 20, 2661-2680

Bhattacharya, A., and Steward, R. (2002). The Drosophila homolog of NTF-2, the nuclear transport factor2 , is essential for immune response. EMBO Rep. 3, 378-383.

Borg, M., Brownfield, L., Khatab, H., Sidorova, A., Lingaya, M., and Twell, D. (2011). The R2R3 MYB transcription factor DUO1 activates a male germline-specific regulon essential for sperm cell differentiation in Arabidopsis. Plant Cell 23, 534-549.

Burch-Smith, T. M., Schiff, M., Caplan, J. L., Tsao, J., Czymmek, K., and Dinesh-Kumar, S. P. (2007). A novel role for the TIR domain in association with pathogen-derived elicitors. PLoS Biol. 5:e68. doi: 10.1371/journal.pbio.0050068

Caillaud, M.-C., Piquerez, S. J. M., Fabro, G., Steinbrenner, J., Ishaque, N., Beynon, J., et al. (2012a). Subcellular localization of the Hpa RxLR effector repertoire identifies a tonoplast-associated protein HaRxL17 that confers enhanced plant susceptibility. Plant J. 69, 252-265.

Caillaud, M.-C., Wirthmueller, L., Fabro, G., Piquerez, S. J. M., Asai, S., Ishaque, N., et al. (2012b) Mechanisms of nuclear suppression of host immunity by effectors from the Arabidopsis downy mildew pathogen Hyaloperonospora arabidopsidis (Hpa). Cold Spring Harb. Symp. Quant. Biol. [Epub ahead of print].

Caplan, J., Padmanabhan, M., and Dinesh-Kumar, S. P. (2008). Plant NB-LRR immune receptors: from recognition to transcriptional reprogramming. Cell Host Microbe 3, 126-135.

Cardarelli, F., Bizzarri, R., Serresi, M., Albertazzi, L., and Beltram, F. (2009). Probing nuclear localization signalimportin alpha binding equilibria in living cells. J. Biol. Chem. 284, 3663836646

Chang, C.-W., Counago, R. L. M. Williams, S. J., Boden, M., and Kobe, B. (2012). Crystal structure of rice importin- $\alpha$ and structural basis of its interaction with plant-specific nuclear localization signals. Plant Cell 24, 5074-5088.

Cheng, Y. T., Germain, H., Wiermer M., Bi, D., Xu, F., Garcia, A. V., et al. (2009). Nuclear pore complex component MOS7/Nup88 is required for innate immunity and nuclear accumulation of defense regulators in Arabidopsis. Plant Cell 21, 2503-2516.

Cohen, S., Etingov, I., and Panté, N. (2012). Effect of viral infection on the nuclear envelope and nuclear pore complex. Int. Rev. Cell Mol. Biol. 299, 117-159.

Conti, E., Uy, M., and Leighton, L. (1998). Crystallographic analysis of the recognition of a nuclear localization signal by the nuclear import factor karyopherin- $\alpha$. Cell 94 , 193-204.

Cressman, D. E., O’Connor, W. J., Greer S. F., Zhu, X. S., and Ting, J. P. (2001). Mechanisms of nuclear import and export that control the subcellular localization of class II transactivator. J. Immunol. 167, 3626-3634.

Deslandes, L., and Rivas, S. (2011). The plant cell nucleus: a true arena for the fight between plants and pathogens. Plant Signal. Behav. 6, 42-48.

Deslandes, L., Olivier, J., Peeters, N. Feng, D. X., Khounlotham, M. Boucher, C., et al. (2003). Physical interaction between RRS1-R, a protein conferring resistance to bacterial wilt, and PopP2, a type III effector targeted to the plant nucleus. Proc. Natl. Acad. Sci. U.S.A. 100, 8024-8029.

Dias, S. M. G., Cerione, R. A., and Wilson, K. F. (2010). Unloading RNAs in the cytoplasm. Nucleus 1, 139-143.

Dias, S. M. G., Wilson, K. F., Rojas, K. S., Ambrosio, A. L. B., and Cerione, R. A. (2009). The molecular basis for the regulation of the cap-binding complex by the importins. Nat. Struct. Mol. Biol. 16, 930-937.

Fagerlund, R., Kinnunen, L., Köhler, M., Julkunen, I., and Melén, K. (2005). $\mathrm{NF}-\mathrm{kB}$ is transported into the nucleus by importin a3 and importin a4. J. Biol. Chem. 280, 15942-15951.

Fagerlund, R., Melen, K., Kinnunen, L., and Julkunen, I. (2002). Arginine/lysine-rich nuclear localization signals mediate interactions between dimeric STATs and importin a5. J. Biol. Chem. 277, 30072-30078.

Feys, B. J., Moisan, L. J., Newman, M A., and Parker, J. E. (2001). Direct interaction between the Arabidopsis disease resistance signaling proteins, EDS1 and PAD4. EMBO J. 20, 54005411.

Feys, B. J., Wiermer, M., Bhat, R. A., Moisan, L. J., MedinaEscobar, N., Neu, C., et al. (2005). Arabidopsis SENESCENCEASSOCIATED GENE101 stabilizes and signals within an ENHANCED DISEASE SUSCEPTIBILITY1 complex in plant innate immunity. Plant Cell 17, 2601-2613.

Fontes, M. R., Teh, T., Jans, D. Brinkworth, R. I., and Kobe, B. (2003). Structural basis for the specificity of bipartite nuclear localization sequence binding by importin-alpha. J. Biol. Chem. 278, 27981-27987.

Garcia, A. V., Blanvillain-Baufume, S., Huibers, R. P., Wiermer, M. Li, G., Gobbato, E., et al. (2010). Balanced nuclear and cytoplasmic activities of EDS1 are required for a complete plant innate immune response. PLoS Pathog. 6:e1000970. doi: 10.1371/journal.ppat.1000970

Ge, Q., Nakagawa, T., Wynn, R. M., Chook, Y. M., Miller, B. C., and Uyeda, K. (2011). Importin-alpha protein binding to a nuclear localization signal of carbohydrate response element-binding protein (ChREBP). J. Biol. Chem. 286, 28119-28127.

Gelvin, S. B. (2010). Finding a way to the nucleus. Curr. Opin. Microbiol. $13,53-58$.

Genoud, T., Schweizer, F., Tscheuschler, A., Debrieux, D., Casal, J. J. Schäfer, E., etal. (2008). FHY1 mediates nuclear import of the lightactivated phytochrome A photoreceptor. PLoS Genet. 4:e1000143. doi: 10.1371/journal.pgen. 1000143

Goldfarb, D. S., Corbett, A. H., Mason, D. A., Harreman, M. T., and Adam, S. A. (2004). Importin $\alpha$ : a multipurpose nuclear-transport receptor Trends Cell Biol. 14, 505-514.

Görlich, D., Henklein, P., Laskey, R. A., and Hartmann, E. (1996a). A 41 amino acid motif in importin-alpha confers binding to importin-beta and hence transit into the nucleus. $E M B O$ J. 15, 1810-1817.

Görlich, D., Kraft, R., Kostka, S. Vogel, F., Hartmann, E., Laskey, R. A., etal. (1996b). Importin provides a link between nuclear protein import and U snRNA export. Cell 87, 21-32.

He, S., Huang, K., Zhang, X., Yu, X., Huang, P., and An, C. (2011). The LSD1-type zinc finger motifs of Pisum sativa LSD1 are a novel nuclear localization signal and interact with importin alpha. PLoS ONE 6:e22131. doi: 10.1371/journal.pone.0022131
Hodel, A. E., Harreman, M. T., Pulliam, K. F., Harben, M. E., Holmes, J. S., Hodel, M. R., et al. (2006). Nuclear localization signal receptor affinity correlates with in vivo localization in Saccharomyces cerevisiae. J. Biol. Chem. 281, 23545-23556.

Hodel, M. R., Corbett, A. H., and Hodel, A E. (2001). Dissection of a nuclear localization signal. J. Biol. Chem. 276, 1317-1325.

Hruz, T., Laule, O., Szabo, G., Wessendorp, F., Bleuler, S., Oertle, L., et al. (2008). Genevestigator v3: a reference expression database for the meta-analysis of transcriptomes. Adv. Bioinformatics 2008, 420747.

Hu, J., Wang, F., Yuan, Y., Zhu, X., Wang, Y., Zhang, Y., et al. (2010). Novel importin-alpha family member Kpn $\alpha 7$ is required for normal fertility and fecundity in the mouse. J. Biol. Chem. 285, 33113-33122.

Huang, J.-G., Yang, M., Liu, P., Yang, G.-D., Wu, C.-A., and Zheng, C.-C. (2010). Genome-wide profiling of developmental, hormonal or environmental responsiveness of the nucleocytoplasmic transport receptors in Arabidopsis. Gene 451, 38-44.

Huang, T. T., Kudo, N., Yoshida, M., and Miyamoto, S. (2000). A nuclear export signal in the $\mathrm{N}$ terminal regulatory domain of $\mathrm{I} \kappa \mathrm{B} \alpha$ controls cytoplasmic localization of

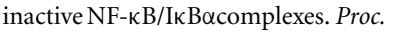
Natl. Acad. Sci. U.S.A. 97, 1014-1019.

Jiang, C. J., Shoji, K., Matsuki, R., Baba, A., Inagaki, N., Ban, H., et al. (2001). Molecular cloning of a novel importin alpha homologue from rice, by which Constitutive Photomorphogenic 1 (COP1) nuclear localization signal (NLS)-protein is preferentially nuclear imported. J. Biol. Chem. 276, 9322-9329.

Johnson, C., Van Antwerp, D., and Hope, T. J. (1999). An N-terminal nuclear export signal is required for the nucleocytoplasmic shuttling of I $\mathrm{B} \alpha$. EMBO J. 18, 6682-6693.

Jones, J. D. G., and Dangl, J. L. (2006). The plant immune system. Nature 444, 323-329.

Kaminaka, H., Näke, C., Epple, P., Dittgen, J., Schütze, K., Chaban, C., et al. (2006). bZIP10-LSD1 antagonism modulates basal defense and cell death in Arabidopsis following infection.EMBO J. 25, 4400-4411.

Kanneganti, T.-D. D., Bai, X., Tsai, C.-W. W., Win, J., Meulia, T., Goodin, M., et al. (2007b). A functional genetic assay for nuclear trafficking in plants. Plant J. 50, 149-158.

Kanneganti, T. D., Lamkanfi, M., and Nunez, G. (2007a). Intracellular 
NOD-like receptors in host defense and disease. Immunity 27, 549-559.

Kelley, J. B., Talley, A. M., Spencer, A., Gioeli, D., and Paschal, B. M. (2010). Karyopherin alpha7 (KPNA7), a divergent member of the importin alpha family of nuclear import receptors. BMC Cell Biol. 11:63. doi: 10.1186/1471-2121-11-63

Kinkema, M., Fan, W. H., and Dong, X. N. (2000). Nuclear localization of NPR1 is required for activation of PR gene expression. Plant Cell 12, 2339-2350.

Kobe, B. (1999). Autoinhibition by an internal nuclear localization signal revealed by the crystal structure of mammalian importin alpha. Nat. Struct. Biol. 6, 388-397.

Köhler, M., Ansieau, S., Prehn, S., Leutz, A., Haller, H., and Hartmann, E. (1997). Cloning of two novel human importin- $\alpha$ subunits and analysis of the expression pattern of the importin- $\alpha$ protein family. FEBS Lett. 417, 104-108.

Köhler, M., Speck, C., Christiansen, M., Bischoff, R., Prehn, S., Haller, H. et al. (1999). Evidence for distinct substrate specificities of importin $\alpha$ family members in nuclear protein import evidence for distinct substrate specificities of importin $\alpha$ family members in nuclear protein import Mol. Cell Biol. 19, 7782-7791.

Kosugi, S., Hasebe, M., Entani, T., Takayama, S., Tomita, M., and Yanagawa, H. (2008). Design of peptide inhibitors for the importin $\alpha \beta$ nuclear import pathway by activitybased profiling. Chem. Biol. 15, 940-949.

Larkin, M. A., Blackshields, G., Brown, N. P., Chenna, R., McGettigan, P. A., McWilliam, H., et al. (2007). Clustal W and Clustal X version 2.0 Bioinformatics 23, 2947-2948.

Lim, C. P., and Cao, X. (2006). Structure, function, and regulation of STAT proteins. Mol. Biosyst. 2, 536-550.

Liu, J., and Coaker, G. (2008). Nuclear trafficking during plant innate immunity. Mol. Plant 1 411-422.

Liu, L., McBride, K. M., and Reich, N. C. (2005). STAT3 nuclear import is independent of tyrosine phosphorylation and mediated by importin- $\alpha 3$. Proc. Natl. Acad. Sci. U.S.A. 102 8150-8155.

Lott, K., Bhardwaj, A., Sims, P. J., and Cingolani, G. (2011). A minimal nuclear localization signal (NLS) in human phospholipid scramblase 4 that binds only the minor NLSbinding site of importin alphal. J. Biol. Chem. 286, 28160-28169.
Maekawa, T., Kufer, T. A., and SchulzeLefert, P. (2011). NLR functions in plant and animal immune systems: so far and yet so close. Nat. Immunol. 12 817-826.

Malek, S., Chen, Y., Huxford, T., and Ghosh, G. (2001). IkB $\beta$, but not $\mathrm{IkB} \alpha$, functions as a classical cytoplasmic inhibitor of NF- $\kappa \mathrm{B}$ dimers by masking both NF- $\kappa \mathrm{B}$ nuclear localization sequences in resting cells. $J$. Biol. Chem. 276, 45225-45235.

Marfori, M., Lonhienne, T. G. Forwood, J. K., and Kobe, B. (2012). Structural basis of highaffinity nuclear localization signal interactions with importin- $\alpha$. Traffic $13,532-548$.

Marfori, M., Mynott, A., Ellis, J. J., Mehdi, A. M., Saunders, N. F. W., Curmi, P. M., et al. (2011). Molecular basis for specificity of nuclear import and prediction of nuclear localization. Biochim. Biophys. Acta 1813 1562-1577.

Matsuura, Y., and Stewart, M. (2004). Structural basis for the assembly of a nuclear export complex. Nature 432 872-877.

Meier, I., and Somers, D. E. (2011). Regulation of nucleocytoplasmic trafficking in plants. Curr. Opin. Plant Biol. 14, 538-546.

Meissner, T. B., Li, A., Liu, Y. J., Gagnon, E., and Kobayashi, K. S. (2012). The nucleotide-binding domain of NLRC5 is critical for nuclear import and transactivation activity. Biochem. Biophys. Res. Commun. 418 , 786-791.

Melén, K., Fagerlund, R., Franke, J., Kohler, M., Kinnunen, L., and Julkunen, I. (2003). Importin alpha nuclear localization signal binding sites for STAT1, STAT2, and influenza A virus nucleoprotein. J. Biol. Chem. 278, 28193-28200.

Melén, K., Kinnunen, L., and Julkunen, I. (2001). Arginine/lysinerich structural element is involved in interferon-induced nuclear import of STATs. J. Biol. Chem. 276, 1644716455.

Merkle, T. (2011). Nucleo-cytoplasmic transport of proteins and RNA in plants. Plant Cell Rep. 30, 153-176.

Meyers, B. C., Lee, D. K., Vu, T. H., Tej, S. S., Edberg, S. B., Matvienko, M., et al. (2004). Arabidopsis MPSS. An online resource for quantitative expression analysis 1 [ w ]. Analysis 135, 801-813.

Miyamoto, Y., Imamoto, N., Sekimoto, T., Tachibana, T., Seki, T., Tada, S., et al. (1997). Differential modes of nuclear localization signal (NLS) recognition by three distinct classes of NLS receptors. J. Biol. Chem. 272, 26375-26381.
Mou, Z., Fan, W. H., Dong X. N., and Carolina, N. (2003). Inducers of plant systemic acquired resistance regulate NPR1 function through redox changes. Cell 113 935-944.

Nadler, S. G., Tritschler, D., Haffar, O. K. Blake, J., Bruce, A. G., and Cleaveland, J. S. (1997). Differential expression and sequence-specific interaction of karyopherin alpha with nuclear localization sequences. J. Biol. Chem. 272, 4310-4315.

Nürnberger, T., Brunner, F., Kemmerling, B., and Piater, L. (2004). Innate immunity in plants and animals: striking similarities and obvious differences. Immunol. Rev. 198, 249-266.

Ouyang, S., Zhu, W., Hamilton, J., Lin, H., Campbell, M., Childs, K., et al. (2007). The TIGR rice genome annotation resource: improvements and new features. Nucleic Acids Res. 35, D883-D887.

Palma, K., Zhang, Y., and Li, X. (2005). An importin alpha homolog MOS6, plays an important role in plant innate immunity. Curr. Biol. 15, 1129-1135.

Park, C. J., and Ronald, P. C. (2012). Cleavage and nuclear localization of the rice XA21 immune receptor. Nat. Commun. 3, 920.

Pitzschke, A., and Hirt, H. (2010). New insights into an old story: Agrobacterium-induced tumour formation in plants by plant transformation. EMBO J. 29, 1021-1032.

Quensel, C., Friedrich, B., Sommer, T., Hartmann, E., and Kohler M. (2004). In vivo analysis of importin $\alpha$ proteins reveals cellular proliferation inhibition and substrate specificity. Mol. Cell. Biol. 24, 1024610255

Ratan, R., Mason, D. A., Sinnot, B. Goldfarb, D. S., and Fleming, R. J. (2008). Drosophila importin alphal performs paralog-specific functions essential for gametogenesis. Genetics 178, 839-850.

Ribbeck, K., Lipowsky, G., Kent, H. M., Stewart, M., and Gorlich, D. (1998). NTF2 mediates nuclear import of Ran. EMBO J. 17, 6587-6598.

Riddick, G., and Macara, I. G. (2005). A systems analysis of importin- $\alpha$ $\beta$ mediated nuclear protein import. $J$ Cell Biol. 168, 1027-1038.

Ronald, P. C., and Beutler, B. (2010). Plant and animal sensors of conserved microbial signatures. Science 330, 1061-1064.

Shen, Q. H., and Schulze-Lefert, P. (2007). Rumble in the nuclear jungle: compartmentalization, trafficking, and nuclear action of plant immune receptors. $E M B O$ J. 26, 4293-4301.

Shen, Q. H., Saijo, Y., Mauch, S., Biskup, C., Bieri, S., Keller, B., et al. (2007). Nuclear activity of MLA immune receptors links isolatespecific and basal disease-resistance responses. Science 315, 10981103.

Slootweg, E., Roosien, J., Spiridon, L. N., Petrescu, A. J., Tameling, W., Joosten, M., et al. (2010). Nucleocytoplasmic distribution is required for activation of resistance by the potato NB-LRR receptor $\mathrm{Rx} 1$ and is balanced by its functional domains. Plant Cell 22, 4195-4115.

Smith, A., Brownawell, A., and Macara, I. G. (1998). Nuclear import of Ran is mediated by the transport factor NTF2. Curr. Biol. 8, 14031406.

Spilianakis, C., Papamatheakis, J., and Kretsovali, A. (2000). Acetylation by PCAF enhances CIITA nuclear accumulation and transactivation of major histocompatibility complex class II genes. Mol. Cell. Biol. 20, 8489-8498.

Stewart, M. (2007). Molecular mechanism of the nuclear protein import cycle. Nat. Rev. Mol. Cell Biol. 8, 195-208.

Tada, Y., Spoel, S. H., PajerowskaMukhtar, K., Mou, Z., Song, J., Wang, C., etal. (2008). Plant immunity requires conformational charges of NPR1 via S-nitrosylation and thioredoxins. Science 952, 952-956.

Tameling, W. I. L., Nooijen, C., Ludwig, N., Boter, M., Slootweg, E., Goverse, A., etal. (2010). RanGAP2 mediates nucleocytoplasmic partitioning of the NB-LRR immune receptor Rx in the Solanaceae, thereby dictating Rx function. Plant Cell 22, 41764194.

Tamura, K., Dudley, J., Nei, M., and Kumar, S. (2007). MEGA4: molecular evolutionary genetics analysis (MEGA) software version 4.0. Mol. Biol. Evol. 24, 1596-1599.

Terry, L. J., Shows, E. B., and Wente, S. R. (2007). Crossing the nuclear envelope: hierarchical regulation of nucleocytoplasmic transport. Science 318, 1412-1416.

Timney, B. L., Tetenbaum-Novatt, J., Agate, D. S., Williams, R., Zhang, W., Chait, B. T., et al. (2006). Simple kinetic relationships and nonspecific competition govern nuclear import rates in vivo. J. Cell Biol. 175, 579-593.

Tsuji, L., Takumi, T., Imamoto, N., and Yoneda, Y. (1997). Identification of novel homologues of mouse 
importin $\alpha$, the $\alpha$ subunit of the nuclear pore-targeting complex, and their tissue-specific expression. FEBS Lett. 416, 30-34.

Wiermer, M., Feys, B. J., and Parker, J. E. (2005). Plant immunity: the EDS1 regulatory node. Curr. Opin. Plant Biol. 8, 383-389.

Wirthmueller, L., Zhang, Y., Jones, J. D. G., and Parker, J. E. (2007). Nuclear accumulation of the Arabidopsis immune receptor RPS4 is necessary for triggering EDS1-dependent defense. Curr. Biol. 17, 2023-2029.

Yano, R., Oakes, M., Yamaghishi, M., Dodd, J. A., and Nomura,
M. (1992). Cloning and characterization of SRPI, a suppressor of temperature-sensitive RNA polymerase I mutations, in Saccharomyces cerevisiae. Mol. Cell. Biol. 12, 5640-5651.

Yasuhara, N., Shibazaki, N., Tanaka, S., Nagai, M., Kamikawa, Y., Oe, S., et al (2007). Triggering neural differentiation of ES cells by subtype switching of importin-alpha. Nat. Cell Biol. 9, 72-79.

Zhu, Y., Qian, W., and Hua, J. (2010). Temperature modulates plant defense responses through NB-LRR proteins. PLoS Pathog. 6:e1000844. doi: 10.1371/journal. ppat. 1000844

Conflict of Interest Statement: The authors declare that the research was conducted in the absence of any commercial or financial relationships that could be construed as a potential conflict of interest.

Received: 04 February 2013; accepted: 02 May 2013; published online: 21 May 2013.

Citation: Wirthmueller L, Roth C, Banfield MJ and Wiermer M (2013) Hopon hop-off: importin- $\alpha$-guided tours to the nucleus in innate immune signaling. Front. Plant Sci. 4:149. doi: 10.3389/ fpls.2013.00149

This article was submitted to Frontiers in Plant-Microbe Interaction, a specialty of Frontiers in Plant Science.

Copyright (c) 2013 Wirthmueller, Roth, Banfield and Wiermer. This is an openaccess article distributed under the terms of the Creative Commons Attribution License, which permits use, distribution and reproduction in other forums, provided the original authors and source are credited and subject to any copyright notices concerning any third-party graphics etc. 